\title{
REGIONAL CLIMATE CHANGE (KARELIA, RUSSIA)
}

\author{
Larisa Nazarova \\ Northern Water Problems Institute, Karelian Research Center \\ Russian Academy of Sciences \\ A. Nevsky st. 50, Petrozavodsk, 185030, Russia \\ Ph.: +(8142)576381, fax: +(8142)578464, e-mail: nazarova@ nwpi.krc.karelia.ru
}

\begin{abstract}
The overview of climatic conditions in Karelia is based on the data from meteorological observations carried out in 1951-2009 at Roskomgidromet weather stations situated in the study area. Taking the period in question into account, the mean annual air temperature norm has increased by $0.2-0.3^{\circ} \mathrm{C}$. The greatest deviation from multiyear averages of mean monthly air temperature is observed in January and March. The investigation of the changes the basic regional climate characteristics is very important in present time because the global climate is changed. The analysis the data about air temperature and precipitation, that were obtained for the different meteorological stations in the investigated region, shows that the regional climate is changed and the main tendencies are directly proportional to the change of the global characteristics.
\end{abstract}

Keywords: regional climate change, air temperature.

\section{Introduction}

A topical problem of today is climate variability and change in the context of global warming. Tendencies of climate change at the regional level are of particular interest. According to observation data, the global climate system has been changing since the early $20^{\text {th }}$ century. Climate data for Russian Karelia were summarized in the 1960s-1980s. Obviously, changes of the last 15-20 years remained unaccounted. And it is during this time that patterns of change appear most interesting in view of global climate warming. Close analysis of regional climatic distinctions, study of the response of natural systems to climate change through representative observations is a good way to address the challenges of climate change.

\section{Materials and methods}

The temperature regime in Karelia was studied on the basis of data from air temperature monitoring at the republic's weather stations (WS) in the period from 1951 to 2009.

\section{Results}

Among-year averages of mean annual air temperature range from $0{ }^{\circ} \mathrm{C}$ in northern parts of the study area to $+2.6 \ldots+2.8{ }^{0} \mathrm{C}$ in the south of the republic. The highest mean annual air temperature norms were recorded from Lake Ladoga area $\left(+3.0^{\circ} \mathrm{C}\right.$ at Sortavala WS \& +3.3 ${ }^{0} \mathrm{C}$ at Valaam WS). In the second half of the $20^{\text {th }}$ and first decade of the $21^{\text {st }}$ century, mean annual air temperature had a positive trend throughout Karelia. Since 1988, annual air temperature means have nearly always been higher than the climatic norm determined for the period of 1961-1990 (Fig. 1).

The rise in mean annual air temperature over the territory has been uneven. The highest linear trend coefficients were obtained from the weather stations located in southern parts of the republic, on Lake Ladoga coast: Olonets WS $-+0.34{ }^{0} \mathrm{C} / 10$ yrs., Sortavala WS $-+0.3{ }^{0} \mathrm{C} / 10$ yrs. (Fig. 2). In central parts of Karelia, the upward trend in mean annual air temperature is not so explicit: $+0.26 \ldots+0.27{ }^{0} \mathrm{C} / 10$ yrs. Values of the linear warming trend coefficient of mean annual air temperature are the lowest in the northern part of the study area: ca. +0.2 
${ }^{0} \mathrm{C} / 10$ yrs. Thus, the intensity of mean annual air temperature rise in the region grows gradually from higher to lower latitudes.

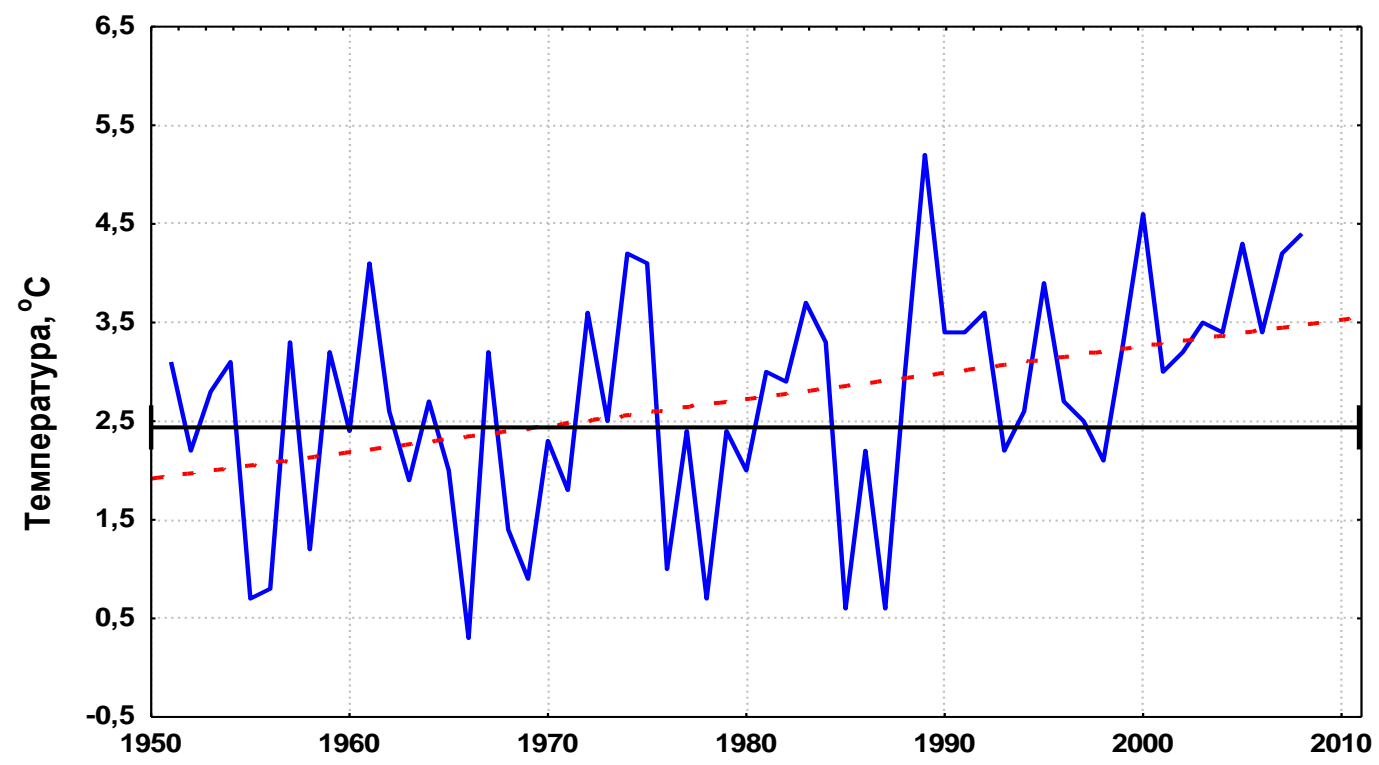

Fig. 1. Changes in mean annual air temperature at Petrozavodsk WS from 1951 to 2009 (dash line - linear trend, solid line - climatic norm for 1961-1990)

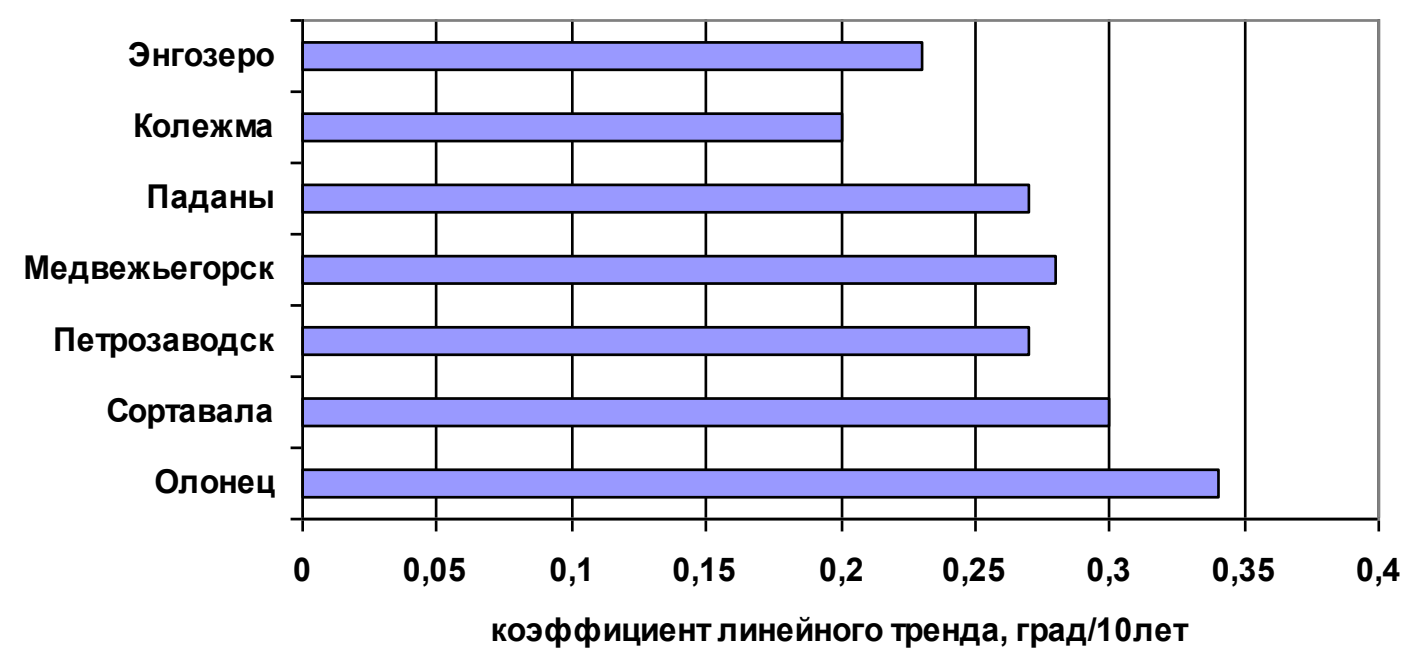

Fig. 2. Values of linear trend coefficients of main annual air temperature based on data from weather stations of Karelia recorded in 1951-2009

In contrast to the Leningrad, Pskov and Novgorod Regions, the climate in Karelia features zonal distribution of all temperature characteristics throughout the year: mean monthly air temperature, dates of temperature transition across certain points, total temperatures, and other meteorological characteristics. The temperature conditions are the most severe in northern areas, higher than $64^{\circ} \mathrm{N}$. Winter is the coldest in the north-western part of the republic, which is dissected by spurs of the Maanselkä ridge; winter in the White Sea lowland is quite mild. Further towards the south of the region, temperature conditions become less harsh. The temperature conditions most favourable for people to live in are in the southern part of the republic, the climate being the mildest in south-western districts, which adjoin 
Lake Ladoga. Air temperature in the coldest month ranges from $-9^{\circ} \mathrm{C}$ close to Lake Ladoga to $-12^{\circ} \mathrm{C}$ in the north-west of the republic. In the vicinity of large lakes and on islands of Lakes Ladoga and Onega, February is colder than January by an average of $0.2-0.5^{\circ} \mathrm{C}$. July temperatures range from $+16^{\circ} \mathrm{C}$ in southern parts to $+14^{\circ} \mathrm{C}$ in the White Sea area.

Mean monthly air temperatures change unevenly within a year (Fig. 3). Warming has been most intensive is March $\left(+0.5 \ldots+0.6{ }^{0} \mathrm{C} / 10\right.$ yrs.) and January (from $+0.3{ }^{0} \mathrm{C} / 10$ yrs. in northern to +0.6 in southern districts). The February temperature increase is also quite significant, $0.4{ }^{0} \mathrm{C} / 10 \mathrm{yrs}$. over the whole of the republic. From May to December, with the exception of July and August, warming proceeds evenly throughout the region. In August, cooling tendencies have been reported from northern and central Karelia.

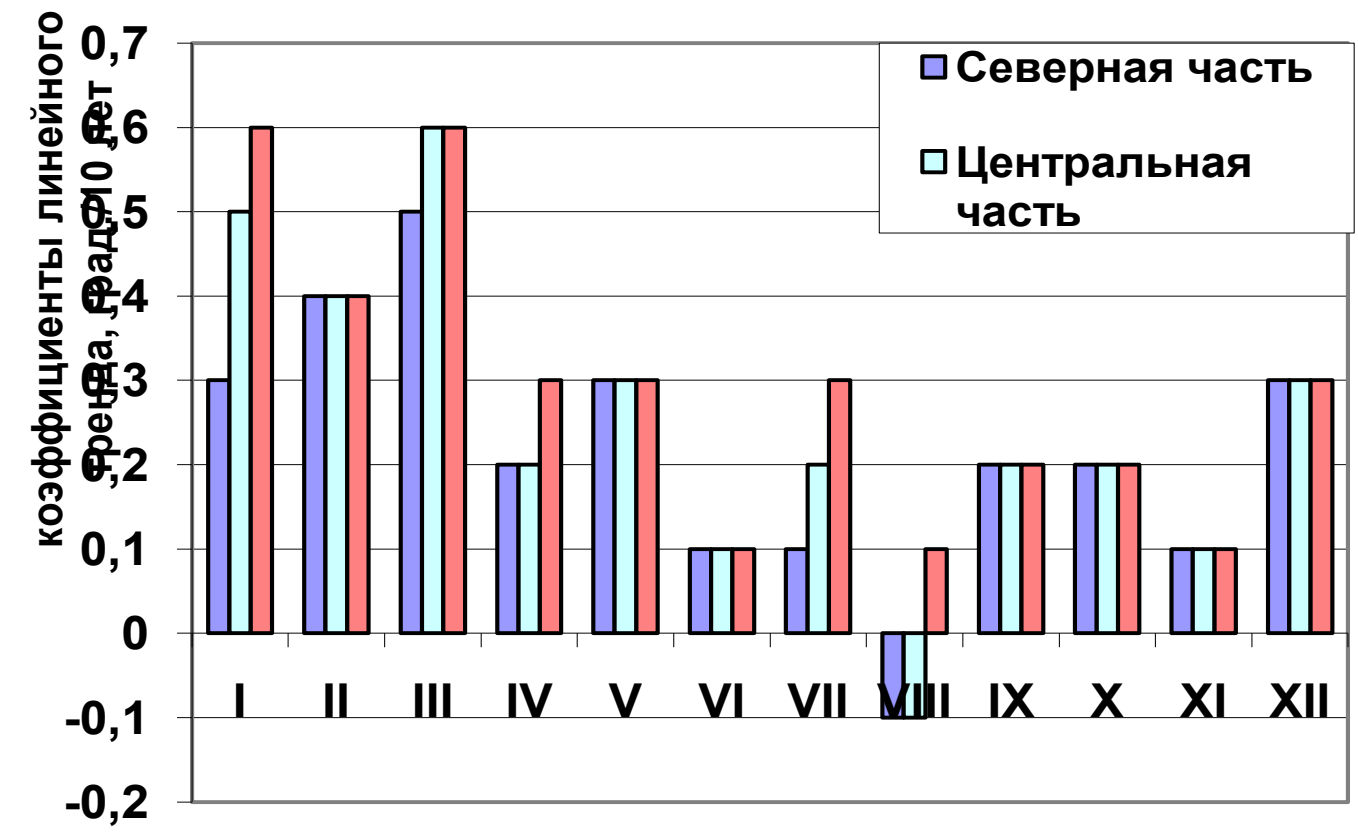

\section{Fig. 3. Values of air temperature linear trend coefficients $\left({ }^{0} \mathrm{C} / 10\right.$ yrs. $)$ by months over the period of 1951-2009 in the study area}

For a more comprehensive description of the region's temperature regime one should consider mean and annual dates when climatic seasons of the year begin and end. Computations have shown the dates when air temperatures established above or below $0,5 \& 10{ }^{\circ} \mathrm{C}$ in years 2000-2009 had a shift relative to multiannual averages. The greatest deviations from the climatic norm were demonstrated by the dates of the warm season beginning and end (above 0 ${ }^{\circ} \mathrm{C}$ ). The cold season arrived 5-23 days later than the average multiannual date. The exception was year 2002, when mean daily air temperature established below $0{ }^{\circ} \mathrm{C}$ ten days earlier than the climatic norm. In 2000-2008, the cold season ended 10-20 days earlier than the multiannual average, except for 2007, when it ended a month earlier, and 2008, when mean daily air temperature established above $0{ }^{\circ} \mathrm{C}$ exactly on the average multiannual date. As the result of the deviations from average dates of steady air temperature transition across $0{ }^{\circ} \mathrm{C}$, the duration of the warm season averaged for the time segment in question was 215- 225 days vs. the 192-210 days of the climatic norm.

A rise in air temperature and average number of days with air temperature above certain points is characteristic of the temperature regime throughout Karelia. Thus, the number of days with mean daily air temperature steadily above $5{ }^{\circ} \mathrm{C}$ in the first decade of the $21^{\text {st }}$ century on average was 148 days in the north of Karelia, and 170 days in central and southern parts, the climatic norm being $134 \&$ 151-159 days, respectively. The number of days with air temperature above $10{ }^{\circ} \mathrm{C}$ was $7-13$ days greater than the norm. 
Changes in the temperature regime in Karelia have influenced the ice regime of lakes. The duration of the ice-free period on Lake Onega has increased from an average of 215 days/year late in the $19^{\text {th }}$ century to an average of 227 days/year early in the $21^{\text {st }}$ century (Fig. 4). The weightiest factor behind the extension of the ice-free period has been air temperature increase in March, which made the ice cover disintegrate 8-10 days earlier.

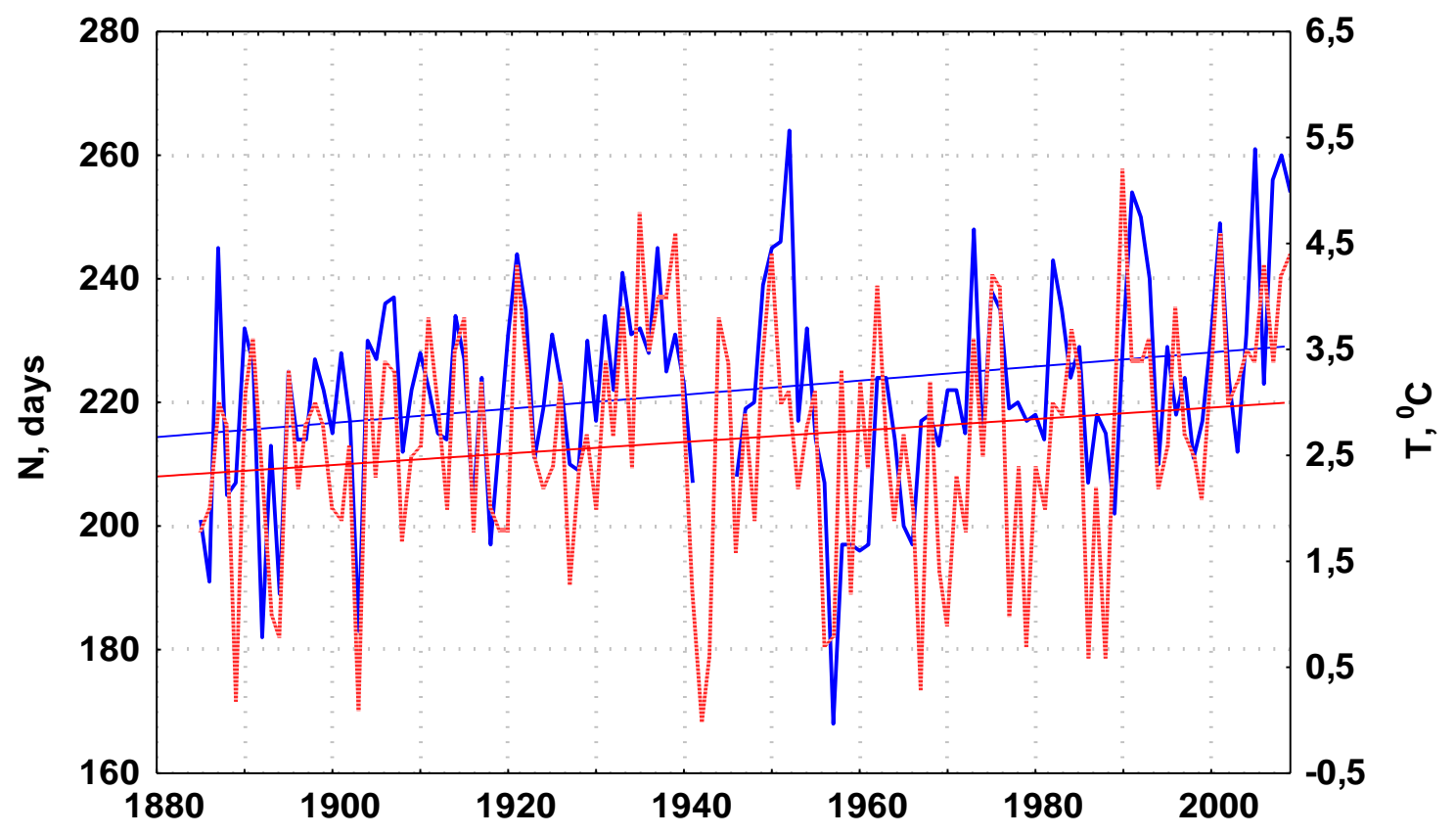

Fig. 4. Duration of the ice-free period (days) for Lake Onega according to data from the Town of Voznesenje (solid line), and mean annual air temperature $\left({ }^{0} \mathrm{C}\right)$ according to data from Petrozavodsk WS (dash line)

\section{Summary}

The analysis the data about air temperature and precipitation, that were obtained for the different meteorological stations in the investigated region, shows that the regional climate is changed and the main tendencies are directly proportional to the change of the global characteristics.

The work is performed under support of the Russian Fund of Basic Research (project № 1005-00963-a). 